good as those obtained with any jelly and the method is far less messy and much cleaner. One does not even need to use a towel to dry the patient off afterwards as the surgical spirit evaporates.

C R RAINIER-POPE

Medical Centre,
Vereeniging 1930, South Africa

\section{Saxophonist's diverticulosis}

SIR,-Further to Dr L D Gardner's letter (26 May, p 1428) drawing attention to the extravagant claim for oral pressure made by the saxophonist with diverticulosis (5 May, p 1217), I am at a loss to understand the pathogenic mechanism proposed for saxophonist's diverticulosis, even if the oral pressures generated had been more physiological.

The incomplete Valsalva manoeuvre performed by the blowing saxophonist would be expected to increase intra-abdominal pressure equally on both sides of the colonic wall. I would find more acceptable a description of saxophonist's hernia, piles, varicose veins, or even perphonic petomania.

Gareth J G ReES

Radiotherapy Centre,

Bristol Royal Infirmary,

Bristol BS2 8ED

\section{PUVA and solariums}

SIR,-While the DHSS continue to bombard dermatologists using PUVA therapy for skin diseases with warnings of potential long-term hazards, of which most of us are aware, it might perhaps be more appropriate for them to direct their warnings to the ever-increasing number of the normal population who are attending commercially run solariums or have their own private units and are receiving doses of ultraviolet $\mathrm{A}$ in excess of those given by us to our patients.

I recently examined two commercially available solarium units and measured the UVA output with a Waldmann black ray meter, which is used to calibrate our departmental SAS unit. Both "health lamps" had an emission of approximately $15 \mathrm{~mW}$ at nine inches, whereas our own unit gives approximately $10 \mathrm{~mW}$ at the same distance. Once the customer acquires a tan he or she is encouraged to attend weekly for half-hourly "treatment" to maintain the tan. On my calculations this involves a dose of approximately 30 joules UVA a week.

The DHSS is also right to draw our attention to the possible side effects of the psoralens themselves, but it is also possible to obtain a therapeutic dose of psoralens from the diet. I saw one patient, a tailor's cutter, who developed friction blisters on the first three digits of the right hand where his scissors caused pressure. He had recently bought a UVA health lamp and was also a food faddist in that he ate large quantities of celery, parsnip, and fresh citrus fruits, all of which contain psoralen. Friction blisters in patients undergoing PUVA therapy have been described. ${ }^{1}$ This patient's blisters subsided when he abandoned his UVA lamp.

It is probable that the only way of determining the long-term effects of PUVA therapy will be to administer it to a large number of patients carefully followed over many years, but, should our attempts to give PUVA to a select group be thwarted by officialdom, on present-day trends there will be a vast number of the population available for study who have submitted themselves to this form of therapy at their own hands.

Royal Infirmary,
Sunderland SR2 7JE

T C Hindson

${ }^{1}$ McGibbon, D H, and Briffa, D, Clinical and Experimental Dermatology, 1978, 3, 371 .

Amitriptyline plasma concentrations and clinical response

SIR,-We agree with $\mathrm{Dr} T \mathrm{~T}$ Norman and others in their letter (31 March, p 894) that investigations of the relation between plasma antidepressant concentrations and clinical response should be conducted in those groups of patients who are most likely to benefit from trycyclic antidepressant therapy. With this in mind, we included in our study (27 January, p 230) only hospital patients with a diagnosis of endogenous depression, as defined by recognised scales, who did not respond during a placebo treatment period. Unfortunately, the concise presentation of our report has led Dr Norman to misunderstand some of our results.

The mean response rate, measured by a decrease on the Hamilton rating scale (HRS), of patients who developed plasma concentrations inside our proposed therapeutic range of 80-200 $: \mathrm{g} / \mathrm{l}$ amitriptyline plus nortriptyline was not $58^{\circ}{ }_{0}$ as stated by Dr Norman, but a satisfactory $72^{\circ}{ }^{\circ}$ improvement. In contrast, the mean response rate of those patients with plasma concentrations outside this range was only $42 \%$. The difference in response between these two groups was highly significant irrespective of whether final HRS score, amelioration score, or percentage change in HRS score was used $(P<0 \cdot 001)$. Furthermore, non-parametric statistical analysis produced similar results.

Reanalysing our data along the lines suggested by Dr Norman, we have compared the clinical response of those patients with plasma concentrations inside and outside the suggested therapeutic range. The criterion for clinical response was set, as in our earlier study, ${ }^{1}$ at a final HRS score of 8 or less. Twenty-nine of the 38 patients with plasma concentrations within the 80-200 $\mu \mathrm{g} / \mathrm{l}$ range responded $\left(76^{\circ}{ }_{0}\right)$, compared with only 10 out of 27 patients $\left(37^{\circ}{ }_{0}\right)$ with plasma concentrations outside this range $\left(\chi^{2}=10 \cdot 2, P<0.005\right)$. Measurement of drug plasma concentrations was carried out by gas chromatography," which has been shown by external quality control tests to be extremely reliable, with a variation index of only $0 \cdot 25 .{ }^{3}$ The figure shows the mean percentage change on the HRS with increasing plasma concentrations of amitriptyline plus nortriptyline for the 65 patients completing our study. The seven patients whose plasma concentrations were below $80 ; \mathrm{g} / \mathrm{l}$ had a poor mean response $\left(38^{\prime \prime}\right)$. There was no apparent difference in response for the three groups of patients with plasma concentrations of $80-120$, 120-160, and 160-200 $\because \mathrm{g} /$; while the 20 patients with plasma concentrations in excess of $200: \mathrm{g} / \mathrm{l}$ showed a successively poorer response with increasing plasma concentrations.

Where previous studies have included only small numbers of patients there is an increased chance that the plasma drug concentrations

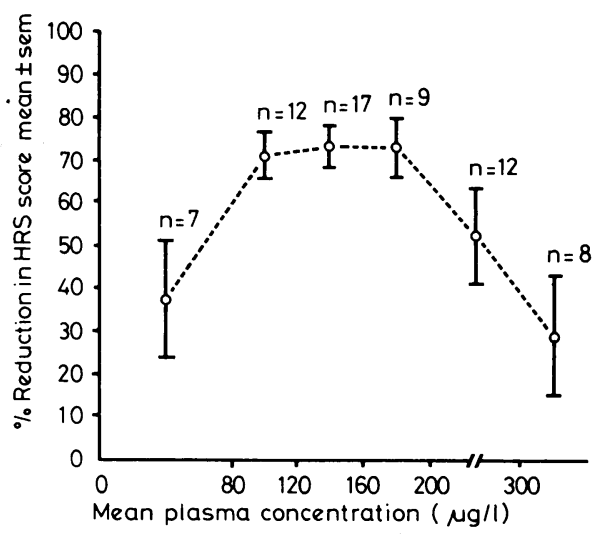

Mean percentage change in HRS ( \pm SE of mean) according to plasma concentrations of amitriptyline plus nortriptyline.

observed will form a cluster. Such an occurrence at low concentrations may well produce a positive linear correlation between plasma drug concentration and clinical response, ${ }^{45}$ while a preponderance of high concentrations could produce a seemingly negative one. ${ }^{16}$ This phenomenon may produce results from different trials which appear to be contradictory but are in fact complementary. When a large, well-conducted study such as ours is completed these apparent contradictions are largely reconciled, and the true curvilinear relation between plasma concentrations of amitriptyline and clinical response is revealed.

\section{S A MONTGOMERY R MCAULEY S J RANI}

Psychiatric Research Unit,

Preston Hall Hospital, Maidstone, Kent ME20 7N

D R MONTGOMERY

R BraithWAite

S DAWLING

Poisons Unit,

Guy's Hospital,

London SE1

Montgomery, S A, et al, Clinical Pharmacology and Therapeutics, 1978, 23, 309.

Dawling, S, and Braithwaite, R A, fournal of Chromatography, 1978, 146, 449.

3 Jones, S, and Turner, P, British Medical fournal,1979,

2, 1217 .
- Braithwaite, R A, et al, Lancet, 1972, 1, 1297.

Ziegler, V E, et al, Archives of General Psychiatry,

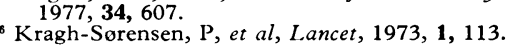

\section{Historical fats}

SIR,-Y Your journal (2 June, $p$ iv) carried an advertisement from the Butter Information Council which could be misleading. The heading of the advertisement states, "If you were convinced that the population is not eating any more animal fat than it was in 1909-would it make you stop and think ?" If we accept the truth of the statement, it is still misleading, because the quality of animal fat in 1909 was almost certainly different from the quality of animal fat at the present time. The animal feeding was completely different -for example, the soft fat pig was considered of good quality, whereas today the bacon factories want only hard fat pigs. Also the dripping sold in 1909 contained unsaturated fatty acids as opposed to the present hard cooking fats and lards, which contain only saturated fats.

The point I am making is that within the total amount of animal fat consumed in 1909 
there was a considerably higher proportion of unsaturated fatty acids, which may be very relevant in the prevention of the modern Western-world epidemic of arterial atheroma. Incidentally I do eat and enjoy butter but balance the saturated fats in my diet with plenty of unsaturated ones.

\section{ROBERT WIGGLESWORTH}

\author{
Kettering and District Genera \\ Hospital, \\ Kettering, Northamptonshire
NN16 8UZ
}

\section{Anaesthetic deaths and caesarean section}

SIR,-While agreeing with everything advocated by Dr B H Goodrich (21 April, p 1079), I would like to make a plea for more caesarean sections to be performed under epidural blocks. While there is still, and always will be, a place for general anaesthesia, especially when there is an urgent need for rapid delivery, an epidural block would seem to have many advantages in cases where time allows. We have been performing caesarean sections under epidurals for three years, and as the benefits of this method become appreciated we are now using it with increasing frequency. One of the big advantages is, of course, that the mother is awake to see the baby at the moment of delivery and hold and cuddle it soon afterwards.

M R FELI

Odstock Hospital,
Salisbury SP2 8BJ

\section{“Strange Encounters"}

SIR,-“"Strange Encounters" makes extraordinary reading. At first I was amusedthen amazed-then dumbfounded-then furious-that such things happened in our profession. Then I wondered if they were fabricated but came to the conclusion that no editor would allow it. I assumed Will Macredie (cunning camouflage) must be some wellknown Scottish physician or surgeonprobably, I don't know why, I thought a surgeon. But I could not find him in my 10year-old Medical Directory. I looked many times, as the listed clans of Macs and Mcs are a terrifying sight. You could easily miss the fellow in all that blether. He didn't sound like a graduate of recent vintage, unless there was a new species in our midst. So I thought I would wait till I could get a look at a current number. Needless to say he is not there-nor in the Medical Register. Or shall I say he isn't where he ought to be in that wild maze of names?

So, is he one or many? I hope the latter. Surely all those things haven't happened to one man?

\section{Newport, Dyfed SA42 0NR}

J D SPillane

${ }^{*} *$ Yes, they have.-ED, BMF.

\section{Lethal cigarettes}

SIR,-I find that exhorting patients to give up smoking is more lastingly effective if followed by an invitation to place any cigarettes they may have on their person into my wastepaper basket. After momentary surprise and hesitation, most accept this challenge.
This symbolic act adds weight to their resolve, and at the same time provides me with a useful byproduct.

One hundred cigarettes, collected by this method in a few days, are brought to the boil in a quart of water and simmered gently for half an hour. The resulting infusion is strained through muslin, and a further half gallon of water added.

For this simple exercise in health education, the practitioner is rewarded by a generous and unending supply of insecticide garden spray, lethal to greenfly and caterpillars.

Dudley, West Midlands

P J EDwin

\section{Ethics, strikes, and the GMC}

SIR,-The 1978 report of the General Medical Council makes on the whole welcome reading: for instance, paediatricians will be glad to see finally buried (deans and faculties please note) the notion that medicine, surgery, and obstetrics should any longer be regarded as primus inter pares among hospital specialties.

But one thing needs to be said on the subject of medical ethics. We live in an age of collectives and in a producer-not a consumersociety; and the major way in which physicians are likely "to exploit their privileges for reasons other than the patient's interests" is now not by individual actions but by mass withdrawal in labour in disputes over pay and conditions. Such action should be specifically outlawed by the General Medical Council as incompatible with the responsibilities of a profession which has been effectively granted a monopoly in supplying a vital human need. In exchange our near-monopoly employer should refer our case with that of other professions similarly situated to the Comparability Commission.

Of course, it would be difficult for the General Medical Council to strike the whole profession off its register-but not impossible if one considers what registration entails.

\section{Department of Child Health,}

JOHN A Davis

Manchester Lniversity

\section{Rubella vaccination}

SIR,-You report in Medical News (9 June, p 1571) that the DHSS is to launch a campaign in mid-June with the aim of reducing the incidence of rubella in women of childbearing age by increasing the proportion of schoolgirls accepting vaccination from the present $70^{\circ}$ to $90-95^{\circ}{ }_{0}$. I must ask whether the decision to offer this procedure at such a young age was originally based on any sound evidence of its likely efficacy, and whether the duration of immunity produced has been shown to be satisfactory? I have reason to doubt it.

Nearly 18 months ago I started to ask women consulting me for contraceptive advice to answer a simple questionnaire with "yes," "no," or "don't know" as follows: (1) Have you had German measles? (2) Have you been vaccinated against German measles? (3) Have you had your blood tested for immunity against German measles? (4) If so, when and where? (5) If not, would you like a blood test to check your immunity against
German measles? (6) If the test shows you are susceptible to German measles, would you like to be vaccinated against it? I have not had time, or the means, to analyse the results fully, but several points are emerging quite clearly: In the first place, few women appear to be able to remember accurately whether they have had rubella, and even fewer can remember whether they were vaccinated against rubella while at school.

A disappointingly small proportion of the women, mostly those who were younger or single, were willing to undergo blood tests for the levels of immunity to rubella to be estimated, and, surprisingly, some of those who insisted that they had been vaccinated against rubella while at school were found to have inadequate levels of antibodies against rubella.

In the light of my experience, I think that the DHSS should reconsider its aims, and perhaps offer vaccination against rubella to those women who are wanting to start having their families, so that the procedure can be carried out at least three months before they stop whatever method of contraception they are using. This would provide safer family planning.

London NW3 4 PS

Philip Hopkins

\section{Tine and Mantoux tuberculin tests}

SIR,-Drs J A Lunn and A J Johnson reported (3 June 1978, p 1451) poor specificity of the tuberculin tine test when compared with the Mantoux test. Tuberculin tine tests have proved useful in our hands in clinical practice over a number of years following an unpublished trial we carried out in 1962 using Mantoux $10 \mathrm{TU}$ and tine tests. In this trial we achieved $98 \%$ correlation in patients suffering from active tuberculosis.

Following Lunn and Johnson's paper we decided to repeat our trial using two groups. One group came from Heatherton Hospital, where most of the tuberculous patients in Melbourne are admitted either for diagnosis or for the start of chemotherapy. The second group was a series of children attending a suburban chest clinic as contacts for follow-up tuberculin testing two years or more after BCG vaccination. In each group a standard Mantoux test, $10 \mathrm{TU}$, was carried out on one arm using purified protein derivative (PPD) supplied by the Commonwealth Serum Laboratories, Melbourne, Australia, and at the same time a tine test was carried out on the other arm using tine discs supplied by Lederle. The Commonwealth Serum Laboratories, main suppliers of tuberculin in Australia, have over the years maintained a constant standard of tuberculin production and advised that a Mantoux test using 10 TU of their product is equivalent to testing with 5 TU of PPD. In Australia a standard Mantoux test is therefore carried out using $10 \mathrm{TU}$ of Commonwealth Serum Laboratories PPD.

The hospital tests were all carried out by one of us and read at 72 hours. At the chest clinic methods were the same except that tests were read at 48 hours by two experienced observers. $5 \mathrm{~mm}$ or more of induration was read as positive for the Mantoux tests and $2 \mathrm{~mm}$ or more at any one of the tine punctures positive for the tine test. The results are shown in the table. In addition, seven subjects, proved to be non-tuberculous, were negative 